\title{
Maternal super-obesity and perinatal outcomes in Australia: a national population-based cohort study
}

Elizabeth A. Sullivan ${ }^{1,2^{*}}$, Jan E. Dickinson ${ }^{3}$, Geraldine A Vaughan ${ }^{1}$, Michael J. Peek ${ }^{4,5}$, David Ellwood ${ }^{6,7}$,

Caroline SE Homer ${ }^{1}$, Marian Knight ${ }^{8}$, Claire McLintock ${ }^{9}$, Alex Wang ${ }^{1}$, Wendy Pollock ${ }^{10,11}$,

Lisa Jackson Pulver ${ }^{12}$, Zhuoyang Li', Nasrin Javid', Elizabeth Denney-Wilson', Leonie Callaway ${ }^{13,14}$

and on behalf of the Australasian Maternity Outcomes Surveillance System (AMOSS)

\begin{abstract}
Background: Super-obesity is associated with significantly elevated rates of obstetric complications, adverse perinatal outcomes and interventions. The purpose of this study was to determine the prevalence, risk factors, management and perinatal outcomes of super-obese women giving birth in Australia.
\end{abstract}

Methods: A national population-based cohort study. Super-obese pregnant women (body mass index $(\mathrm{BMI})>50 \mathrm{~kg} / \mathrm{m}^{2}$ or weight $>140 \mathrm{~kg}$ ) who gave birth between January 1 and October 31, 2010 and a comparison cohort were identified using the Australasian Maternity Outcomes Surveillance System (AMOSS). Outcomes included maternal and perinatal morbidity and mortality. Prevalence estimates calculated with $95 \%$ confidence intervals (Cls). Adjusted odds ratios (ORs) were calculated using multivariable logistic regression.

Results: 370 super-obese women with a median BMl of $52.8 \mathrm{~kg} / \mathrm{m}^{2}$ (range $40.9-79.9 \mathrm{~kg} / \mathrm{m}^{2}$ ) and prevalence of 2.1 per 1000 women giving birth ( $95 \% \mathrm{Cl}$ : 1.96-2.40). Super-obese women were significantly more likely to be public patients (96.2\%), smoke (23.8\%) and be socio-economically disadvantaged (36.2\%). Compared with other women, super-obese women had a significantly higher risk for obstetric (adjusted odds ratio (AOR) 2.42, 95 \% Cl: 1.77-3.29) and medical (AOR: 2.89, $95 \%$ Cl: 2.64-4.11) complications during pregnancy, birth by caesarean section (51.6\%) and admission to special care (HDU/ICU) (6.2\%). The 372 babies born to 365 super-obese women with outcomes known had significantly higher rates of birthweight $\geq 4500 \mathrm{~g}$ (AOR 19.94, $95 \%$ Cl: 6.81-58.36), hospital transfer (AOR 3.81, $95 \%$ Cl: 1.93-7.55) and admission to Neonatal Intensive Care Unit (NICU) (AOR 1.83, 95 \% Cl: 1.27-2.65) compared to babies of the comparison group, but not prematurity (10.5\% versus $9.2 \%$ ) or perinatal mortality (11.0 (95 \% Cl: 4.3-28.0) versus 6.6 (95 \% Cl: 2.6- 16.8) per 1000 singleton births).

Conclusions: Super-obesity in pregnancy in Australia is associated with increased rates of pregnancy and birth complications, and with social disadvantage. There is an urgent need to further address risk factors leading to super-obesity among pregnant women and for maternity services to better address pre-pregnancy and pregnancy care to reduce associated inequalities in perinatal outcomes.

Keywords: Super-obesity, Obesity, Perinatal outcomes, Pregnancy, Maternal socio-economic disadvantage, Obstetric complications

\footnotetext{
* Correspondence: elizabeth.sullivan@uts.edu.au

${ }^{1}$ Faculty of Health, University of Technology Sydney, PO Box 123, Broadway

NSW, 2007 Sydney, Australia

${ }^{2}$ School of Women's and Children's Health, The University of New South

Wales, Sydney, Australia

Full list of author information is available at the end of the article
}

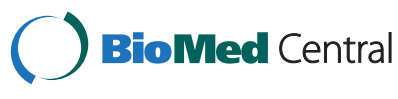

(c) 2015 Sullivan et al. Open Access This article is distributed under the terms of the Creative Commons Attribution 4.0 International License (http://creativecommons.org/licenses/by/4.0/), which permits unrestricted use, distribution, and reproduction in any medium, provided you give appropriate credit to the original author(s) and the source, provide a link to the Creative Commons license, and indicate if changes were made. The Creative Commons Public Domain Dedication waiver (http://creativecommons.org/publicdomain/zero/1.0/) applies to the data made available in this article, unless otherwise stated. 


\section{Background}

The prevalence of obesity (body mass index (BMI) $\geq$ $30 \mathrm{~kg} / \mathrm{m}^{2}$ ) among women of reproductive age continues to rise in developed countries, with Australia at $28.3 \%$ among the highest in the world ahead of United Kingdom [1] and similar to the United States. It is estimated that about one in five women giving birth in Australia are obese [2]. Of increasing concern is the rising rate of socalled super-obesity, defined as a BMI of $\geq 50 \mathrm{~kg} / \mathrm{m}^{2}$ in pregnancy, or women weighing $225 \%$ of ideal body weight $[3,4]$. Super-obesity is associated with significantly elevated rates of obstetric complications, adverse perinatal outcomes and interventions including pre-eclampsia, gestational diabetes mellitus (GDM), preterm birth, caesarean section, general anaesthesia, wound infection, intensive care admission, macrosomia, neonatal hypoglycaemia and congenital anomalies [3-6]. However, there has been no national study of super-obesity in Australian women giving birth. A population study from the United Kingdom reported the prevalence of women with BMI $\geq 50 \mathrm{~kg} / \mathrm{m} 2$ as 8.7 per 10000 women giving birth or $0.1 \%$ [7]. In contrast, the prevalence of super-obesity ranged from $1.8 \%$ [4] in a 7-year (2000 to 2006) US retrospective cohort study in Missouri, to $2.2 \%$ for a 12-year (1996 to 2007) case series of 19700 women giving birth in South Carolina [5]. A retrospective 12-year cohort study of 75 432 women giving birth in a Brisbane hospital (Australia) found a significant increase in the proportion of Class III obesity $(\geq 40 \mathrm{~kg} / \mathrm{m} 2)$ during the course of the study [8]. This suggests that the prevalence of super-obesity among women giving birth is also on the rise in Australia although this has not been previously reported [8].

The objective of this study was to determine the prevalence, risk factors, management and perinatal outcomes of super-obese women giving birth in Australia; and to determine the effect of maternal super-obesity on perinatal outcomes compared with other women. We hypothesized that pregnancy in super-obese women compared with other women is associated with a higher risk of maternal morbidity and adverse perinatal outcomes.

\section{Methods}

\section{Study design and population}

A national, prospective cohort study was undertaken using the Australasian Maternity Outcomes Surveillance System (AMOSS). The AMOSS methods have been described in detail elsewhere [9]. Women were identified by participating AMOSS sites, responding to a monthly email that included negative reporting of whether a case had been identified between January and October 2010. Hospital $(n=226)$ sites progressively joined AMOSS on completion of relevant ethics/governance processes and were included for the period they participated in the study. The denominator of 171289 women giving birth was calculated using the number of days of participation in the study multiplied by number of births per day for that hospital and gave approximate coverage of $66 \%$ of all women giving birth in Australia. The case definition included any pregnant woman of 20 weeks' gestation or more who, at any point in pregnancy, had a BMI of greater than $50 \mathrm{~kg} / \mathrm{m}^{2}$ or a weight of more than $140 \mathrm{~kg}$. The case definition was clinician informed with a weight of $>140 \mathrm{~kg}$ at any point in pregnancy considered superobese irrespective of having a BMI $<50 \mathrm{~kg} / \mathrm{m}^{2}$. The comparison group for a series of AMOSS studies were the two women who gave birth immediately before women with placenta accreta and/or women who underwent a peripartum hysterectomy between January 2010 and December 2011 [10]. The comparison group represented the general population of women giving birth in Australia and New Zealand and inclusion criteria did not include BMI, however all comparison women had a BMI $\leq 50 \mathrm{~kg} / \mathrm{m}^{2}$ or weight $\leq 140 \mathrm{~kg}$.

A questionnaire completed by AMOSS site coordinators for all eligible women sought information on demographic and pregnancy factors, obstetric interventions and perinatal outcomes as well as models of antenatal care, specified medical and obstetric complications and bariatric equipment (e.g., high-weight capacity bed, operating table, hoist, chair) availability. Free-text responses to questions regarding medical/obstetric morbidity were categorised according to ICD-10 AM codes.

We anticipated identifying 264 super-obese women and 528 comparison women over 12 months, based on the prevalence of the United Kingdom study of 8.7 per 10000 women giving birth [7]. These numbers give a power of $80 \%$ at the $5 \%$ level of significance to detect difference in proportions of outcomes (gestational diabetes, caesarean section and admission to NICU) by $10 \%$ in study group over a range of incidences from 5 to $30 \%$ in the comparison group.

\section{Other study factors}

The woman's age was calculated in completed years at the time of the antenatal care booking visit and classified into four categories: <25, 25-29, 30-34, and $\geq 35$ years. Other demographic characteristics such as parity $(0,1-2$, and $\geq 3$ ), Indigenous status, marital status, admission as private/public patient, smoking during pregnancy, socioeconomic status (Australian socio-economic indices for areas (SEIFA) of relative advantage/disadvantage quintile) [11], previous caesarean section, multiple pregnancy and assisted reproductive technology treatment were recorded.

\section{Outcomes}

Models of care, obstetric interventions, and birth outcomes were measured for both groups. Health professional involvement during antenatal care, specific medical 
and obstetric complications and bariatric equipment availability were recorded for the super-obese women only.

\section{Statistical analysis}

Prevalence estimates with $95 \%$ confidence intervals (CIs) were calculated. Distribution of BMI was graphically compared between super-obese women and the comparison group. Chi-square or Fisher's exact test was used to investigate difference in obstetric interventions and birth outcomes of study and comparison groups. Multivariable logistic regression was used to examine the medical and obstetric complications (gestational diabetes, gestational hypertension, pre-eclampsia, etc.), labour characteristics (onset of labour and method of delivery), maternal outcomes (admission to ICU or HDU) and perinatal outcomes (birthweight $\geq 4500 \mathrm{~g}$, admission to NICU, and need for transfer). Odds ratio (OR) and adjusted odds ratio (AOR) and $95 \%$ confidence interval (CI) were calculated. Adjustment was made for maternal age, maternal Indigenous status, marital status, admission as private/public patient, smoking status, assisted reproductive technology, parity, multiple gestation and socio-economic status. Any p-values less than 0.05 were considered statistically significant. Data were analysed using the Statistical Package for the Social Sciences software, version 22.0 (IBM Corporation, Somers, NY, USA).

\section{Ethics approval}

Ethics approval for AMOSS was granted by NSW Population and Health Services Research Ethics Committee and multiple Human Research Ethics Committees across Australia [12] and the multiregional ethics approval in New Zealand. The AMOSS studies are considered lowrisk under (Australian) National Health and Medical Research Council (NHMRC) guidelines. The data collected from case notes by onsite AMOSS data coordinators were de-identified, and no consent was required by participants. Data were reported at an aggregate level only [12].

\section{Results}

A total of 370 super-obese pregnant women (297 women had a BMI of greater than $50 \mathrm{~kg} / \mathrm{m}^{2}$ and 73 women had a weight of more than $140 \mathrm{~kg}$ ) were confirmed as cases with an estimated prevalence of 2.14 per 1000 (95\% CI: 1.96-2.40) women giving birth (Fig. 1). Data were available for 621 women in the comparative group. The median BMI (Fig. 2) of the super-obese women was $52.8 \mathrm{~kg} / \mathrm{m}^{2}$ (range, $40.9-79.9 \mathrm{~kg} / \mathrm{m}^{2}$ ) compared to $24.8 \mathrm{~kg} / \mathrm{m}^{2}$ (range, $16.3-48.9 \mathrm{~kg} / \mathrm{m}^{2}$ ) for comparison women. The median weight of super-obese women was $156 \mathrm{~kg}$ (range 108-204 kg) which was over twice the median weight for the comparison women of $67 \mathrm{~kg}$ (range 42-138 kg). Demographic and pregnancy-related

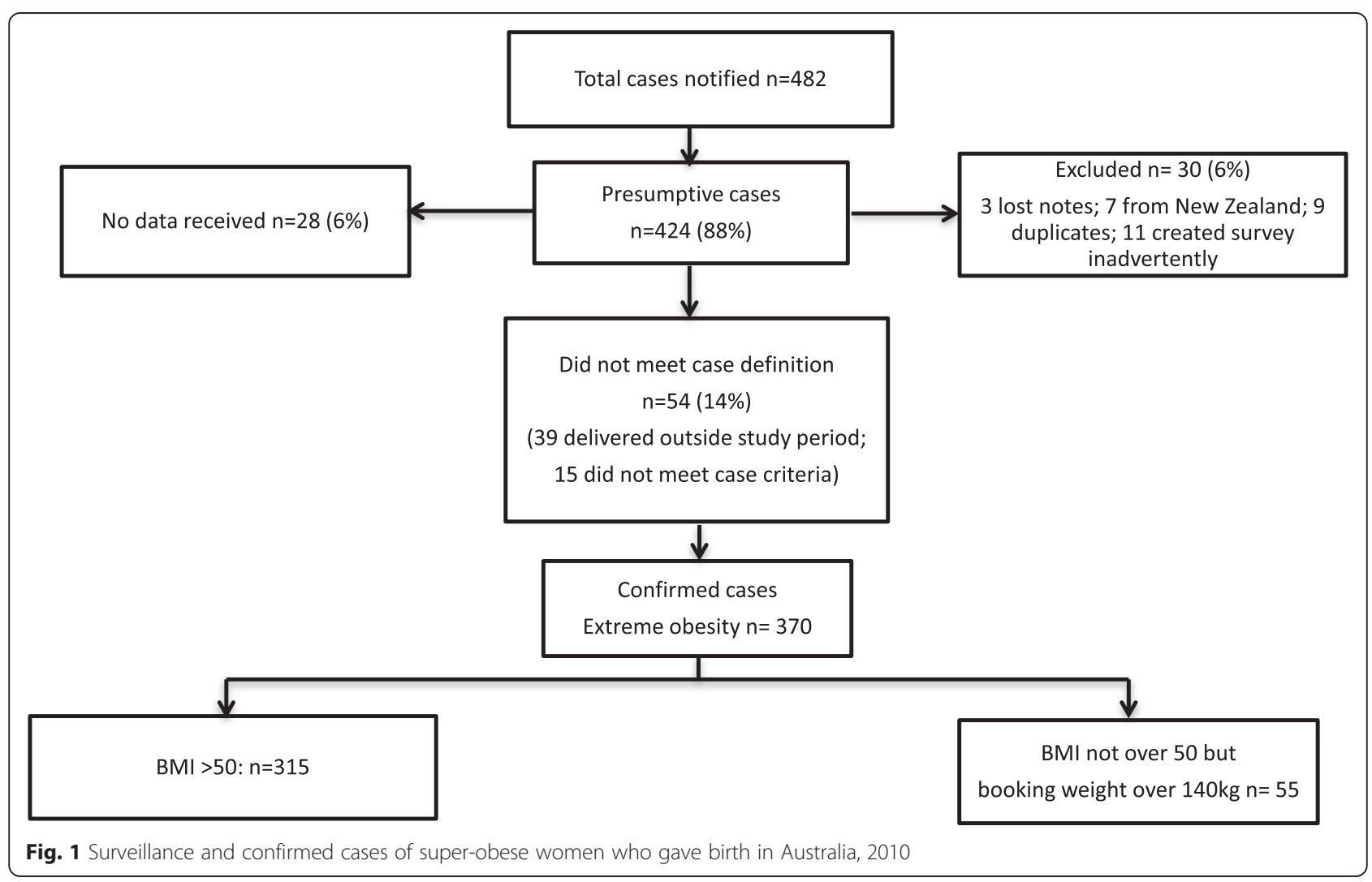




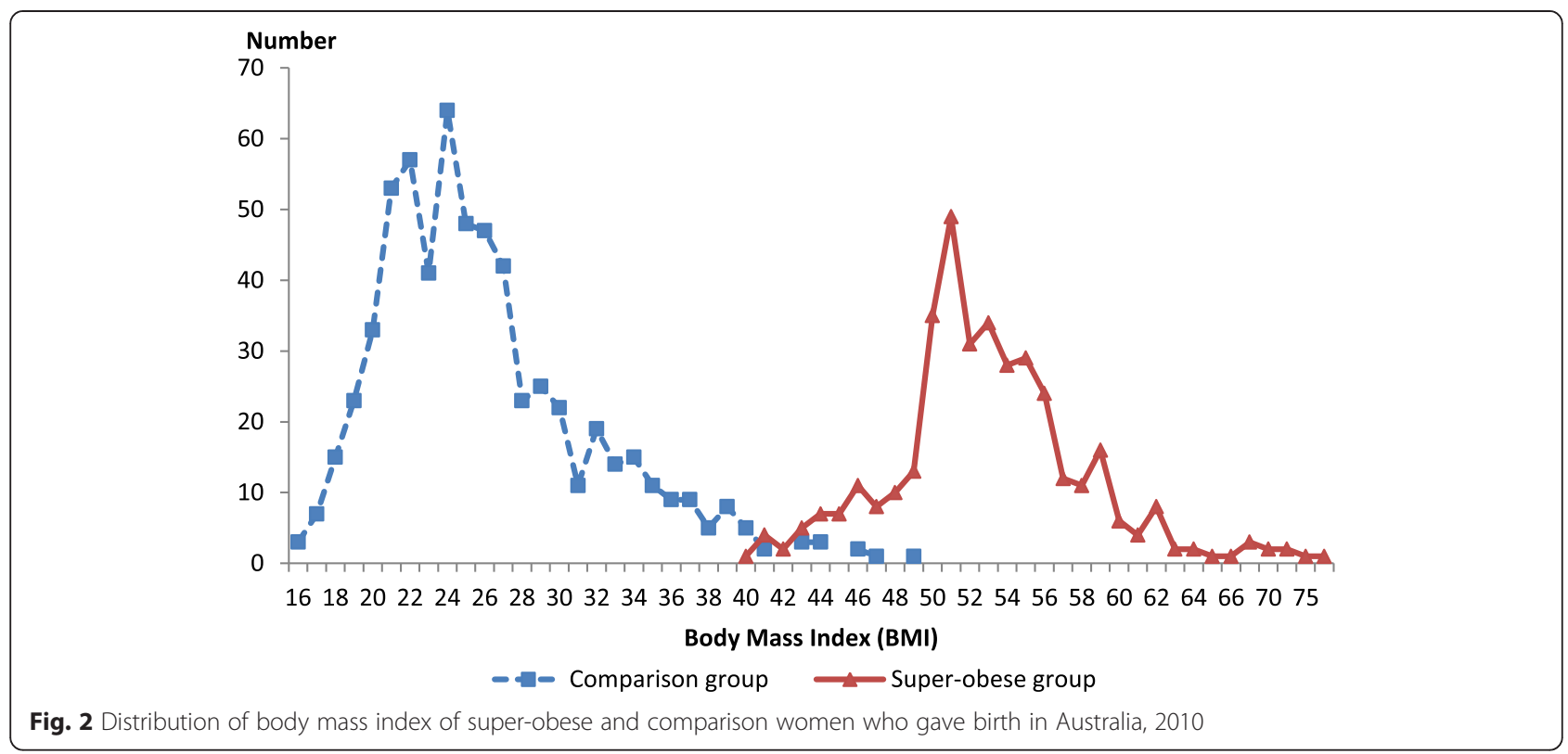

characteristics of super-obese and comparison groups are shown in Table 1. The super-obese women (cases) were of similar age but of significantly higher parity than the comparison women (parity $\geq 3: 22.2 \%$ versus $9.2 \%, p<0.01$ ). They were more likely to smoke (23.8 \% versus $16.1 \%$, $p<0.01$ ), to be socio-economically disadvantaged (lowest SEIFA quintile: $17.8 \%$ versus $7.9 \%, p<0.01)$ and be admitted as a public patient (96.2 \% versus $76.7 \%, p<0.01$ ).

\section{Models of care}

The majority of super-obese women had a hospitalbased, medical model of care with few under the care of midwives or private obstetricians, which was significantly different from the comparison group (Table 2). Changes in the model of care and rates of transfer between hospitals were higher for the super-obese group compared with comparison women (Table 2). Fewer than half ( $n=173,46.8 \%$ ) of the super-obese women saw a dietician during pregnancy, while $70.5 \%(n=261)$ consulted obstetric anaesthetists and $17.8 \%(n=66)$ consulted maternal-fetal medicine specialists during pregnancy (data unavailable for comparison group). Multi-disciplinary meetings were held for $12 \%$ of super-obese women during the antenatal period to plan management.

\section{Medical and obstetric complications during pregnancy}

Super-obese women had significantly higher rates of obstetric (42.0\% versus 23.2 \%; AOR: 2.42, 95 \% CI: $1.77-$ 3.29 ) and medical (33.3\% versus $13.0 \%$; AOR: 2.89, 95 \% CI: 2.64-4.11) complications during pregnancy (Table 3). Super-obese women were significantly more likely to develop gestational diabetes (15.6\% versus $7.2 \%$; AOR: 2.52, 95 \% CI: 1.58-4.65), pre-eclampsia
(8.5 \% versus $2.6 \%$; AOR: 3.43, 95 \% CI: 1.72-6.84) or gestational hypertension (12.3 \% versus $1.5 \%$; AOR: 10.24, $95 \%$ CI: 4.67-22.44) than comparison women. Of the 18 (4.9\%) of super-obese women who had antenatal thromboprophylaxis, nine $(2.4 \%)$ were given low-molecular weight heparin.

\section{Labour and birth}

Compared to the comparison women, the super-obese women were more likely to undergo induction of labour or no labour (Table 4). The likelihood of having caesarean section was significantly higher among super-obese women $(51.6 \%)$ than the comparison women $(31.7 \%)$ (AOR: 2.73, 95 \% CI: 2.02-3.69) with $9.9 \%$ of caesarean section performed under general anaesthesia (Table 3). The most common indications for planned caesarean section were previous CS (72 \%, $n=76)$, abnormal fetal presentation (breech, transverse, or unstable lie (18\%, $n=19)$, macrosomia $(7 \%, n=7)$ and maternal medical complications $(7.5 \%, n=8)$. Shoulder dystocia occurred in 11 (6\%) of super-obese women who gave birth vaginally.

\section{Perinatal outcomes}

Birth outcomes were known for 365 (98.6\%) of the super-obese women $(n=372$ infants, including 7 sets of twins. Super-obese women were significantly more likely to give birth to babies with a birthweight $\geq 4500 \mathrm{~g}$ (AOR: 19.94, 95 \% CI: 6.81-58.36) (Table 4). Thirty-six (9.8\%) of 362 singleton infants born to super-obese women had a birthweight $\geq 4500 \mathrm{~g}$, in contrast to $0.8 \%$ $(n=5 / 608)$ of the singleton infants in the comparison group. Of the 36 singletons with a birthweight $\geq 4500 \mathrm{~g}$, 
Table 1 Demographic and obstetric characteristics among super-obese and comparison women who gave birth in Australia, 2010

\begin{tabular}{llll}
\hline $\begin{array}{llll}\text { Super-obese group } \\
(N=370)\end{array}$ & $\begin{array}{l}\text { Comparison } \\
(N=621)\end{array}$ & $P$ value \\
\cline { 2 - 2 }$\%$ & No. $\%$ & \\
\hline
\end{tabular}

\begin{tabular}{clllll}
\hline Age (years) & & & & & \\
$<25$ & 60 & 16.2 & 99 & 15.9 & 1.00 \\
$25-29$ & 109 & 29.5 & 185 & 29.8 & \\
$30-34$ & 110 & 29.7 & 187 & 30.1 & \\
$\geq 35$ & 91 & 24.6 & 150 & 24.2 &
\end{tabular}

Indigenous status

$\begin{array}{llrlrl}\text { No } & 341 & 92.2 & 572 & 92.1 & 0.23 \\ \text { Yes } & 17 & 4.6 & 19 & 3.1 & \\ \text { Not stated } & 12 & 3.2 & 30 & 4.8 & \end{array}$

Marital status

$\begin{array}{llrlr}\text { Single } & 71 & 19.2 & 71 & 11.4 \\ \text { Married/cohabit } & 277 & 74.9 & 508 & 81.8 \\ \text { Not stated } & 22 & 5.9 & 42 & 6.8\end{array}$

Private health insurance

$\begin{array}{llrlrl}\text { No } & 356 & 96.2 & 474 & 76.3 & <0.01 \\ \text { Yes } & 14 & 3.8 & 145 & 23.3 & \\ \text { Not stated } & 0 & 0.0 & 2 & 0.3 & \end{array}$

Smoking during pregnancy

$\begin{array}{llcccc}\text { No } & 265 & 71.6 & 484 & 77.9 & <0.01 \\ \text { Yes } & 88 & 23.8 & 100 & 16.1 & \\ \text { Not stated } & 17 & 4.6 & 37 & 6.0 & \end{array}$

Assisted reproductive technology

$\begin{array}{lccccc}\text { No } & 357 & 96.5 & 574 & 92.4 & 0.17 \\ \text { Yes } & 11 & 3.0 & 29 & 4.7 & \\ \text { Not stated } & 2 & 0.5 & 18 & 2.9 & \\ \text { Parity } & & & & & \\ 0 & 115 & 31.1 & 251 & 40.4 & <0.01 \\ 1-2 & 173 & 46.8 & 313 & 50.4 & \\ 3+ & 82 & 22.2 & 57 & 9.2 & \\ \text { Multiple gestation pregnancy } & & & & \\ \text { No } & 362 & 97.8 & 608 & 97.9 & 0.81 \\ \text { Yes } & 8 & 2.2 & 12 & 1.9 & \\ \text { Not stated } & 0 & 0.0 & 1 & 0.2 & \\ \text { Socio-economic status } & & & & & \\ \text { Most disadvantage } 1 & 66 & 17.8 & 49 & 7.9 & <0.01 \\ 2 & 68 & 18.4 & 73 & 11.8 & \\ 3 & 109 & 29.5 & 121 & 19.5 & \\ 4 & 80 & 21.6 & 181 & 29.1 & \\ \text { Least disadvantage 5 } & 40 & 10.8 & 191 & 30.8 & \\ \text { Not stated } & 7 & 1.9 & 6 & 1.0 & \end{array}$

Table 1 Demographic and obstetric characteristics among super-obese and comparison women who gave birth in Australia, 2010 (Continued)

\begin{tabular}{|c|c|c|c|c|c|}
\hline \multicolumn{6}{|c|}{ Previous caesarean section (exclude primiparous) } \\
\hline No & 140 & 54.9 & 250 & 67.6 & $<0.01$ \\
\hline Yes & 112 & 43.9 & 115 & 31.1 & \\
\hline Not stated & 3 & 1.2 & 5 & 1.4 & \\
\hline
\end{tabular}

$16.6 \%$ of their mothers had pre-existing diabetes. There was no significant difference in preterm birth between super-obese and comparison women $(n=39 / 370,10.5 \%$ versus $n=57 / 621,9.2 \%$ ) (Table 4 ). Of the singletons born to super-obese women, $22.9 \%(n=83 / 362)$ were admitted to the neonatal intensive care unit (NICU) compared to $13.7 \%(n=83 / 608)$ of singletons in the comparison group (Table 4). The perinatal mortality rate for the infants born to super-obese women was 11.0 per 1000 (95\% CI: 4.3-28.0) singleton births which consisted of four stillbirths (one $<30$ weeks) and no neonatal deaths. There were three stillbirths ( 2 antepartum and 1 intrapartum) among the infants born in the comparison group (all $<30$ weeks) and one neonatal death, giving a perinatal mortality rate of 6.6 per 1000 (95\% CI: 2.6, 16.8) singleton births. Three of the four super-obese

Table 2 Model of care among super-obese and comparison women who gave birth in Australia, 2010

\begin{tabular}{|c|c|c|c|c|c|}
\hline & \multicolumn{2}{|c|}{$\begin{array}{l}\text { Super-obese group } \\
(N=370)\end{array}$} & \multicolumn{2}{|c|}{$\begin{array}{l}\text { Comparison } \\
(N=621) \\
\end{array}$} & \multirow[t]{2}{*}{$P$ value } \\
\hline & No. & $\%$ & No. & $\%$ & \\
\hline \multicolumn{6}{|l|}{ Lead care provider } \\
\hline General practitioner & 72 & 19.5 & 122 & 19.6 & \multirow[t]{5}{*}{$<0.01$} \\
\hline Hospital medical & 247 & 66.8 & 175 & 28.2 & \\
\hline Hospital midwife & 34 & 9.2 & 182 & 29.3 & \\
\hline Private obstetrician & 17 & 4.6 & 140 & 22.5 & \\
\hline Not stated & 0 & 0.0 & 2 & 0.3 & \\
\hline \multicolumn{6}{|l|}{ Changed during pregnancy } \\
\hline No & 312 & 84.3 & 566 & 91.1 & \multirow[t]{3}{*}{$<0.01$} \\
\hline Yes & 56 & 15.1 & 55 & 8.9 & \\
\hline Not stated & 2 & 0.5 & 0 & 0.0 & \\
\hline \multicolumn{6}{|l|}{ Transfer } \\
\hline No & 326 & 88.1 & 596 & 96.0 & \multirow[t]{2}{*}{$<0.01$} \\
\hline Yes & 44 & 11.9 & 25 & 4.0 & \\
\hline \multicolumn{6}{|l|}{ Timing of maternal transfer } \\
\hline Antepartum & 34 & 77.3 & 19 & 76.0 & \multirow[t]{3}{*}{0.77} \\
\hline Intrapartum/Postpartum & 9 & 20.5 & 6 & 24.0 & \\
\hline Not stated & 1 & 2.3 & 1 & 0.0 & \\
\hline
\end{tabular}


Table 3 Labour and birth characteristics among super-obese and comparison women who gave birth in Australia, 2010

\begin{tabular}{|c|c|c|c|c|c|}
\hline & \multicolumn{2}{|c|}{$\begin{array}{l}\text { Super-obese group } \\
(N=370)\end{array}$} & \multicolumn{2}{|c|}{$\begin{array}{l}\text { Comparison } \\
(N=621)\end{array}$} & \multirow[t]{2}{*}{$P$ value } \\
\hline & No. & $\%$ & No. & $\%$ & \\
\hline \multicolumn{6}{|l|}{ Multiple births } \\
\hline Singleton & 362 & 97.8 & 608 & 97.9 & 0.81 \\
\hline Twin & 8 & 2.2 & 12 & 1.9 & \\
\hline Not stated & 0 & 0.0 & 1 & 0.2 & \\
\hline \multicolumn{6}{|l|}{ Labour } \\
\hline No & 125 & 33.8 & 139 & 22.4 & $<0.01$ \\
\hline Yes & 241 & 65.1 & 482 & 77.6 & \\
\hline Not stated & 4 & 1.1 & 0 & 0.0 & \\
\hline \multicolumn{6}{|l|}{ Induction of labour } \\
\hline No & 100 & 41.5 & 351 & 72.8 & $<0.01$ \\
\hline Yes & 140 & 58.1 & 129 & 26.8 & \\
\hline Not stated & 1 & 0.4 & 2 & 0.4 & \\
\hline \multicolumn{6}{|l|}{ Method of birth } \\
\hline Vaginal birth & 176 & 47.6 & 424 & 68.3 & $<0.01$ \\
\hline Caesarean section & 191 & 51.6 & 197 & 31.7 & \\
\hline Not stated & 3 & 0.8 & 0 & 0.0 & \\
\hline \multicolumn{6}{|l|}{ Caesarean section } \\
\hline Planned & 103 & 53.9 & 122 & 61.9 & 0.1 \\
\hline Unplanned & 87 & 45.5 & 73 & 37.1 & \\
\hline Not stated & 1 & 0.5 & 2 & 1.0 & \\
\hline \multicolumn{6}{|c|}{ Use of general anaesthetic } \\
\hline No & 172 & 90.1 & 191 & 97.0 & 0.01 \\
\hline Yes & 19 & 9.9 & 6 & 3.0 & \\
\hline
\end{tabular}

women who had stillbirths reported gestational hypertension compared to none of the comparison women.

\section{Postpartum maternal complications}

Thirteen per cent (49/370) of the super-obese women experienced a postpartum infection; of those, $69 \%(n=34)$ had undergone a caesarean section. The most common infection was wound infection $(n=25,51 \%)$ with 12 (24\%) women having multiple complications from infection. Postnatally, 224 (60.5 \%) super-obese women received thromboprophylaxis, of these, $78.1 \%$ received low-molecular-weight heparin (LMWH). Postnatal thromboprophylaxis was administered in $29.7 \%$ of super-obese women who gave birth vaginally compared to $90.5 \%$ of super-obese women following caesarean section $(p<0.01)$. Of the 18 women who did not receive thromboprophylaxis following caesarean section, two women were aged $>35$ years, six continued to smoke during pregnancy and five had a history of hypertensive disorders (HTD). The median length of stay for super-obese women was 4 days (range 1-32 days). Super-obese women were significantly more likely to be admitted to a High Dependency Unit (HDU) or Intensive Care Unit (ICU) (6.2 \% versus $1.3 \%$; AOR: 5.67, 95 \% CI: 2.31-13.93) compared to the comparison women (Table 4). No maternal deaths were woman reported in either group.

\section{Discussion}

Super-obesity was reported in more than 1 in 500 women giving birth in Australia with these women experiencing higher rates of obstetric complications and adverse perinatal outcomes. Compared to other women, the birth experience of super-obese women was characterised by higher rates of caesarean section, general anaesthesia, admission to HDU and ICU and hospital transfer. Fewer than one in 10 super-obese women accessed a midwifery led model of care or private obstetric care with the usual model of care being a hospitalbased, medical model. Super-obese women had more than twice the risk of caesarean section (CS) with almost half of the CS unplanned and around $10 \%$ conducted under general anaesthesia. Maternal obesity may be an independent risk factor for CS as it interferes with the progress of labour, specifically the arrest of dilation in active phase labour [13]. The higher rate of CS has been explained in other studies by the association of superobesity with conditions such as gestational diabetes, gestational hypertension and preeclampsia [14-16], all of which were more prevalent in women in our study. This is consistent with other research including comparison with other obese women (BMI 30.0-49.9 kg/m²) [5]. Other studies of super-obese women $\left(B M I \geq 50 \mathrm{~kg} / \mathrm{m}^{2}\right)$ have reported higher rates of both early preeclampsia (AOR: 2.97, 95 \% CI: 2.07- 4.26) and late preeclampsia (AOR: 4.79, 95 \% CI: 4.26-5.39) compared with normal weight mothers $\left(\mathrm{BMI}=18.5-24.9 \mathrm{~kg} / \mathrm{m}^{2}\right)$ [6]. While clinicians have raised concerns about ability to monitor progress of labour and assess fetal wellbeing in obese women [17], it is argued that there is insufficient evidence to justify a routine policy of CS for all super-obese women solely because of higher recorded rates of complications, but that the mode of birth should be based on a careful assessment of risk factors [18]. Hospital guidelines and other recommendations would suggest thromboprophylaxis for women in the study group who had caesarean sections is warranted. There is, however, little or no differentiation of risk according to degree of obesity [19-21]; although Martin et al. highlights the dose-response of increased risk of thromboembolic events and eclampsia as BMI increases and suggests this can be usefully applied to other pregnancy-related complications [16]. This amplified risk of morbidity according to BMI is consistent with the Mbah study discussed earlier and showed a significantly increased risk of preeclampsia between super-obese women $\left(\mathrm{BMI} \geq 50 \mathrm{~kg} / \mathrm{m}^{2}\right.$ 
Table 4 Maternal, obstetric and perinatal outcomes among super-obese and comparison women who gave birth in Australia, 2010

\begin{tabular}{|c|c|c|c|c|}
\hline & $\begin{array}{l}\text { Super-obese group } \\
(N=370) \\
\%\end{array}$ & $\begin{array}{l}\text { Comparison } \\
(N=621) \\
\%\end{array}$ & OR & $\mathrm{AOR}^{\mathrm{b}}$ \\
\hline \multicolumn{5}{|l|}{ Complications during pregnancy } \\
\hline Medical problems during pregnancy & 33.3 & 13 & $3.35(2.43-4.62)$ & $2.89(2.64-4.11)$ \\
\hline Obstetric problems during pregnancy & 42 & 23.2 & $2.40(1.81-3.17)$ & $2.42(1.77-3.29)$ \\
\hline Gestational diabetes & 15.6 & 7.2 & $2.36(1.56-3.59)$ & $2.52(1.58-4.65)$ \\
\hline Gestational hypertension & 12.3 & 1.5 & $9.33(4.50-19.33)$ & $10.24(4.67-22.44)$ \\
\hline Preeclampsia & 8.5 & 2.6 & $3.42(1.85-6.35)$ & $3.43(1.72-6.84)$ \\
\hline \multicolumn{5}{|l|}{ Obstetric } \\
\hline Labour & 65.8 & 77.6 & $0.55(0.42-0.74)$ & $0.49(0.35-0.68)$ \\
\hline Induction of labour & 58.3 & 26.9 & $3.81(2.75-5.28)$ & $4.33(3.21-6.24)$ \\
\hline Caesarean section & 52 & 31.7 & $2.33(1.79-3.65)$ & $2.73(2.02-3.69)$ \\
\hline \multicolumn{5}{|l|}{ Perinatal outcomes (singletons only) } \\
\hline Birthweight $\geq 4500 \mathrm{~g}$ & 10.1 & 0.8 & $13.44(5.22-34.57)$ & $19.94(6.81-58.36)$ \\
\hline Admitted to NICU & 23.7 & 13.9 & $1.93(1.38-2.71)$ & $1.83(1.27-2.65)$ \\
\hline Need for transfer & 8.5 & 2.7 & $3.39(1.82-6.31)$ & $3.81(1.93-7.55)$ \\
\hline Preterm birth $<37$ weeks & 10.1 & 8.1 & $1.28(0.81-2.00)$ & $1.18(0.72,1.93)$ \\
\hline \multicolumn{5}{|l|}{ Maternal outcomes } \\
\hline Admission to ICU & 2.2 & 0.5 & $4.56(1.25-17.32)$ & $7.38(1.52-35.87)$ \\
\hline Admission to HDU & 4.3 & 0.8 & $5.58(2.43-15.37)$ & $5.40(1.78-16.38)$ \\
\hline Admission to either ICU or HDU & 6.2 & 1.3 & $5.09(2.25-11.51)$ & $5.67(2.31-13.93)$ \\
\hline
\end{tabular}

adjusted odds ratio 4.71 [4.20-5.28]) compared to women with Class III obesity (3.75 [3.59-3.92] [6].

The number of infants with birth weight $>4500 \mathrm{~g}$ found in our cohort is similar to the UKOSS study of super-obese women that reported a rate of almost nine percent [7]. The long term clinical impact of a high birthweight is unknown. While some studies [22] suggest these infants may have higher rates of obesity and metabolic syndrome in adolescence and adulthood, whether this is a product of the intrauterine environment or of growing up in an environment where children are exposed to sociodemographic factors that promote the development of obesity is uncertain. There were elevated rates of admission of infants to special and intensive care units placing a higher burden on the health system. A perinatal mortality rate of 11.0 per 1000 was not different to that in the comparison group or to national Australian data [23] and was slightly lower than that reported in the UKOSS study on super-obese women (16.0 per 1000) [7]. There was no difference in the rate of preterm birth among super-obese group, so any difference in perinatal outcomes was not related to prematurity.
The rising prevalence of obesity in Australian women of reproductive age suggests that strategies of weight loss, diet, exercise and bariatric surgery have been of limited benefit or that women are not aware of the potential health adverse outcomes associated with obesity in pregnancy. Our study finds that 2.1 per 1000 women giving birth in Australia are super-obese. The Royal Australia and New Zealand College of Obstetricians and Gynaecologists (RANZCOG) recommends pre-conception management of obesity and weight loss through lifestyle approaches of exercise and nutrition, bariatric surgery, nutritional supplementation and psychosocial support. It also recommends that women should have their BMI measures at their first antenatal consultation and, if indicated, multidisciplinary care should be organised to advise and monitor about gestational weight gain, nutritional supplementation, exercise and ensure access to antenatal facilities with appropriate equipment [24].

The National Institute for Health and Clinical Excellence has recommended bariatric surgery as a first-line option for adults with BMI $>50 \mathrm{~kg} / \mathrm{m}^{2}$, instead of lifestyle interventions or drug treatment [25]. Studies have shown that super-obese women who had bariatric surgery prior 
to pregnancy had lower rates of gestational hypertension, pre-eclampsia, gestational diabetes, and macrosomic infants compared with super-obese women who had not had surgery [26-28]. Nutritional deficiencies during pregnancy have been reported among women following bariatric surgery [29] and nutritional follow-up and careful weight gain management should be provided. A recent systematic review suggests that antenatal interventions targeting diet and/or physical activity have mixed results [30]. Some studies show a reduction in maternal weight gain from antenatal dietary intervention but no effect on maternal or infant morbidity. This may reflect the limitation of intervention being focused on dietary advice alone rather than a more holistic approach which provides support for the woman and her general wellbeing. There are little data on interventions in super obese women. Interventions in the postnatal period should be considered to encourage postpartum weight loss and improve outcomes in subsequent pregnancies [31].

A strength of this study was the use of a comparison group that was representative of the women giving birth in Australia [23]. This allowed investigation of whether there was an increased clinical impact and associated burden on health services for women with super obesity. Martin et al. [16] suggest the need for differential management of super-obese pregnant women compared to the lower range of BMI $40-49.9 \mathrm{~kg} / \mathrm{m}^{2}$, including the need for larger antibiotic dosage for women with BMIs of $>50 \mathrm{~kg} / \mathrm{m}^{2}$ to that of women with BMI of $>35 \mathrm{~kg} / \mathrm{m}^{2}$, and a need for more research on the specific anticoagulation requirements according to tiered classification of obesity $[5,16]$. A limitation of this approach is that it potentially decreases the capacity to detect difference in our study between the super-obese group and the comparison group in maternal and perinatal outcomes due to the inclusion of obese women in the comparison group.

A limitation of the study was that there was no specific question on whether the super-obese women had previous bariatric surgery. There was a question on previous abdominal surgery with a free text response possible. Interestingly, nine super-obese women and one control reported gastric banding suggesting that any further research on super-obese women should include questions on bariatric surgery and laparoscopic-bands. Pre conception options for super-obese women may be the insertion of an adjustable laparoscopic band or gastric sleeve procedure prior to pregnancy. These procedures are associated with fewer nutritional deficiencies than bariatric surgery, and several observational studies have reported encouraging results, including lower incidence of gestational diabetes, pregnancy induced hypertension and lower weight gain during pregnancy. However women with adjustable laparoscopic bands require close monitoring from a multidisciplinary team and may need the band adjusted during pregnancy, especially in women with frequent vomiting [32]. Adjustable laparoscopic band surgery and or gastric sleeves are rarely available in the public or Medicare funded hospital system in Australia. In our sample of super obese women, only $3.8 \%$ had private health insurance, and over one third were from the two least advantaged quintiles of socio-economic status, suggesting that lap band surgery pre-pregnancy may not be an option for many women.

Measurement error of BMI is another potential limitation of the study. Despite recommendations for maternal BMI to be recorded at the booking visit $[24,33]$ this was not done at all participating AMOSS sites nor were serial measures of BMI throughout pregnancy available. In a separate survey to participating sites in 2010, BMI at booking was routinely undertaken at $74 \%$ of the 195 sites that responded. There may be some information bias regarding the BMI as weight and/or height could be self-reported or measured depending upon the maternity unit practice. At this level of obesity, some error in the BMI precision is likely to have minimal impact on the generalisability of the results, as alternative measures such as skinfolds are impractical and unreliable in general clinical practice.

A potential limitation of the study was the incremental participation of maternity sites in AMOSS over the course of the study which may have impacted recruitment of cases. Conversely, a strength of the study is that the findings are consistent with routine perinatal data which also demonstrates variation in the prevalence of super-obesity across jurisdictions ranging from 1.8 per 1000 births in NSW [34] to 3.67 per 1000 in Queensland [35] and 4.68 per 1000 births in Western Australia [36]. A second strength was the distribution of participating sites which was representative of Australian maternity services [37].

The increasing prevalence of super-obesity has important implications for maternity services as the evidence suggests current strategies have had limited impact. Super-obesity is associated with and may be a manifestation of complex socio-economic disadvantage and needs innovative interventions and strategies to address underlying health inequity. This study found over a third of super-obese women were in the two most disadvantaged quintiles with only $10.8 \%$ in the least disadvantaged and confirms previous research findings of lower socioeconomic status being associated with super-obesity [38-41]. Super obese women risk substantial comorbidity affecting both them and their offspring. This calls for targeted strategies to address weight gain before, within and between pregnancies, that are appropriate, collaborative and provide training for clinicians within the health services. In the absence of effective 
interventions to enable women to lose weight (or maintain weight) during pregnancy, super-obese women planning a pregnancy should be supported to make lifestyle changes or consider laparoscopic band, gastric sleeve or bariatric surgery prior to pregnancy.

\section{Conclusions}

The findings from our study underline the imperative to prioritise initiatives that address the increased perinatal risks of super-obese women and their babies. The overall resource burden of maternity care for super-obese women was evident with higher rates of obstetric and medical complications, intervention in pregnancy and childbirth, and for infants postnatally. Super-obesity in pregnancy is associated with social disadvantage. There is an urgent need to address pre-pregnancy and pregnancy care and ensure that appropriate initiatives are in place to reduce associated inequalities in perinatal outcomes and future pregnancies of super-obese women.

\section{Competing interests}

The authors declare that they have no competing interests.

\section{Authors' contributions}

All authors have contributed to the conducting of this study. EAS designed the study, interpreted data and drafted the manuscript. GV participated in the study design, assisted in drafting the manuscript and acquired data. $\mathrm{NJ}$ acquired data and assisted in drafting the manuscript. YAW and ZL conducted the data analysis and assisted in drafting the manuscript. JED, MJP, DE, CSEH, MK, WP, LJP, ZL, CM, EDW, and LC have participated in the study design and/or revised the manuscript critically for important intellectual content. The manuscript has been seen and approved by all authors.

\section{Acknowledgements}

The National Health and Medical Research Council Project Grant (Application 510298) for funding The Australian Maternity Outcomes Surveillance System: Improving safety and quality of maternity care in Australia (AMOSS) from 2008-2012. We acknowledge the significant support of participating maternity units and AMOSS data collectors in Australia and New Zealand who participated in the study, as well as the AMOSS Associate Investigators and AMOSS Advisory Group. We acknowledge Yelena Fridgant who assisted in data preparation.

\section{Author details}

${ }^{1}$ Faculty of Health, University of Technology Sydney, PO Box 123, Broadway NSW, 2007 Sydney, Australia. 'School of Women's and Children's Health, The University of New South Wales, Sydney, Australia. ${ }^{3}$ School of Women's and Infants' Health, The University of Western Australia, Perth, Australia. ${ }^{4}$ Department of Obstetrics and Gynaecology Medical School College of Medicine, Biology and Environment, The Australian National University, Canberra, Australia. ${ }^{5}$ Obstetrics and Gynaecology, Centenary Hospital for Women and Children, Canberra, Australia. ${ }^{6}$ School of Medicine, Griffith University, Queensland, Australia. ${ }^{7}$ Gold Coast University Hospital, Queensland, Australia. ${ }^{8}$ National Perinatal Epidemiology Unit, University of Oxford, Oxford, United Kingdom. ${ }^{9}$ Obstetrics and Gynaecology, National Women's Health, Auckland City Hospital, Auckland, New Zealand. ${ }^{10} J u d i t h$ Lumley Centre, La Trobe University, Melbourne, Australia. ${ }^{11}$ Department of Nursing, Melbourne School of Health Sciences, The University of Melbourne, Melbourne, Australia. ${ }^{12}$ Muru Marri Indigenous Health Unit, School of Public Health and Community Medicine, The University of New South Wales, Sydney, Australia. ${ }^{13}$ Royal Brisbane and Women's Hospital, Brisbane, Australia. ${ }^{14} \mathrm{~S}$ chool of Medicine, The University of Queensland, Brisbane, Australia.

Received: 19 February 2015 Accepted: 5 October 2015

Published online: 02 December 2015

\section{References}

1. OECD. Health at a Glance 2013: OECD Indicators. Edited by EOECD. Paris, France: OECD Publishing; 2013.

2. Hilder L, Zhichao Z, Parker M, Jahan S, Chambers G. Australia's mothers and babies 2012. AlHW, editor. Perinatal statistics series no 30. Canberra: AlHW; 2014.

3. Mason EE, Doherty C, Maher JW, Scott DH, Rodriguez EM, Blommers TJ. Super obesity and gastric reduction procedures. Gastroenterol Clin N Am. 1987;16(3):495-502.

4. Marshall NE, Guild C, Cheng YW, Caughey AB, Halloran DR. Maternal superobesity and perinatal outcomes. Am J Obstet Gynecol. 2012;206(5):417. e411-416.

5. Alanis MC, Goodnight WH, Hill EG, Robinson CJ, Villers MS, Johnson DD. Maternal super-obesity (body mass index $>$ or $=50$ ) and adverse pregnancy outcomes. Acta Obstet Gynecol Scand. 2010;89(7):924-30.

6. Mbah A, Kornosky J, Kristensen S, August E, Alio A, Marty P, et al. Super-obesity and risk for early and late pre-eclampsia. Br J Obstet Gynaecol. 2010;117(8):997-1004.

7. Knight M, Kurinczuk J, Spark P, Brocklehurst $P$, on behalf of the UK Obstetric Surveillance System (UKOSS). Extreme Obesity in Pregnancy in the United Kingdom. Am Coll Obstet Gynecol. 2010;115(5):9.

8. Mclntyre HD, Gibbons KS, Flenady VJ, Callaway LK. Overweight and obesity in Australian mothers: epidemic or endemic? Med J Aust. 2012;196(3):184-8.

9. Halliday LE, Peek MJ, Ellwood DA, Homer C, Knight M, McLintock C, et al. The Australasian Maternity Outcomes Surveillance System: An evaluation of stakeholder engagement, usefulness, simplicity, acceptability, data quality and stability. Aust N Z J Obstet Gynaecol. 2012;53(2):152-7.

10. Lindquist A, Noor N, Sullivan E, Knight M. The impact of socioeconomic position on severe maternal morbidity outcomes among women in Australia: a national case-control study. BJOG. 2014. doi:10.1111/1471-0528.13058.

11. ABS. Census of Population and Housing: Socio-Economic Indexes for Areas (SEIFA), Australia, 2011,. In. Edited by ABS. Canberra ACT; 2013.

12. Vaughan G, Pollock W, Peek MJ, Knight M, Ellwood D, Homer CS, et al. Ethical issues: The multi-centre low-risk ethics/governance review process and AMOSS. Aust N Z J Obstet Gynaecol. 2012;52(2):195-203.

13. Verdiales M, Pacheco C, Cohen WR. The effect of maternal obesity on the course of labor. J Perinat Med. 2009;37(6):651-5.

14. Chu S, Kim S, Schmid C, Dietz P, Callaghan W, Lau J, et al. Maternal obesity and risk of cesarean delivery: a meta-analysis. Obesity Reviews. 2007;8(5):385-94.

15. Poobalan A, Aucott L, Gurung T, Smith W, Bhattacharya S. Obesity as an independent risk factor for elective and emergency caesarean delivery in nulliparous women-systematic review and meta-analysis of cohort studies. Obesity Reviews. 2009;10(1):28-35.

16. Martin A, Krishna I, Ellis J, Paccione R, Badell M. Super obesity in pregnancy: difficulties in clinical management. J Perinatol. 2014;34(7):495-502.

17. Schmied VA, Duff M, Dahlen HG, Mills AE, Kolt GS. 'Not waving but drowning': a study of the experiences and concerns of midwives and other health professionals caring for obese childbearing women. Midwifery. 2011;27(4):424-30.

18. Homer CSE, Kurinczuk JJ, Spark P, Brocklehurst P, Knight M. Planned vaginal delivery or planned caesarean delivery in women with extreme obesity. BJOG. 2011;118(4):480-6.

19. McLintock C, Brighton T, Chunilal S, Dekker G, McDonnell N, McRae S, et al. Recommendations for the prevention of pregnancy-associated venous thromboembolism. ANZJOG. 2012;52:3-13.

20. National Health and Medical Research Council: Clinical practice guideline for the prevention of venous thromboembolism (deep vein thrombosis and pulmonary embolism) in patients admitted to Australian hospitals. Melbourne: NHMRC; 2009.

21. The Women's Hospital: Thromboprophylaxis. Caesarean Section. In: Policy, Guideline and Procedure Manual. Melbourne: The Women's Hospital; 2013. p. 4.

22. Catalano PM, Ehrenberg HM. The short- and long-term implications of maternal obesity on the mother and her offspring. BJOG. 2006;113(10):1126-33.

23. Li Z, Zeki R, Hilder L, Sullivan EA. Australia's mothers and babies 2010. In: Perinatal statistics series no 27 Cat no PER 57. Canberra: AlHW National Perinatal Epidemiology and Statistics Unit; 2012.

24. RANZCOG: Management of Obesity in Pregnancy. College statement., vol. C-Obs 49. Melbourne: RANZCOG; 2013: 9.

25. National Institute for Health and Clinical Excellence: Obesity: Guidance on the prevention, identification, assessment and management of overweight 
and obesity in adults and children. Edited by National Institute for Health and Clinical Excellence (NIHCE); 2006.

26. Dalfra MG, Busetto L, Chilelli NC, Lapolla A. Pregnancy and foetal outcome after bariatric surgery: a review of recent studies. J Matern Fetal Neonatal Med. 2012;25(9):1537-43.

27. Lapolla A, Marangon M, Dalfra MG, Segato G, De Luca M, Fedele D, et al. Pregnancy outcome in morbidly obese women before and after laparoscopic gastric banding. Obes Surg. 2010;20(9):1251-7.

28. Weintraub AY, Levy A, Levi I, Mazor M, Wiznitzer A, Sheiner E. Effect of bariatric surgery on pregnancy outcome. Int J Gynaecol Obstet. 2008;103(3):246-51.

29. Eerdekens A, Debeer A, Van Hoey G, De Borger C, Sachar V, Guelinckx I, et al. Maternal bariatric surgery: adverse outcomes in neonates. Eur J Pediatr. 2010;169(2):191-6.

30. Dodd J, Grivell R, Crowther C, Robinson J. Antenatal interventions for overweight or obese pregnant women: a systematic review of randomised trials. BJOG. 2010;117:1316-26.

31. van der Pligt P, Willcox J, Hesketh KD, Ball K, Wilkinson S, Crawford D, et al. Systematic review of lifestyle interventions to limit postpartum weight retention: implications for future opportunities to prevent maternal overweight and obesity following childbirth. Obes Rev. 2013;14(10):792-805.

32. Vrebosch L, Bel S, Vansant G, Guelinckx I, Devlieger R. Maternal and neonatal outcome after laparoscopic adjustable gastric banding: a systematic review. Obes Surg. 2012;22(10):1568-79.

33. Callaway LK, Prins JB, Chang AM, McIntyre HD. The prevalence and impact of overweight and obesity in an Australian obstetric population. Med J Aust. 2006;184(2):56-9.

34. NSW Department of Health. ObstetriX Perinatal data collection. Edited by NSW Department of Health. Sydney: NSW Department of Health; 2010

35. Queensland Health. Perinatal data collection. Edited by Queensland Health. Brisbane: Queensland Health; 2010.

36. Western Australia Department of Health. Perinatal data collection. Edited by WA Department of Health. Perth: Western Australia Department of Health; 2010

37. Homer CSE, Biggs J, Vaughan G, Sullivan EA. Mapping maternity services in Australia: location, classification and services. Aust. Health Rev. 2011;35(2):222-9

38. Heslehurst N, Ells LJ, Simpson H, Batterham A, Wilkinson J, Summerbell CD. Trends in maternal obesity incidence rates, demographic predictors, and health inequalities in 36821 women over a 15-year period. BJOG: An International Journal of Obstetrics \& Gynaecology. 2007;114(2):187-94.

39. Kim SY, Dietz P, England L, Morrow B, Callaghan WM. Trends in prepregnancy obesity in nine states, 1993-2003. Obesity. 2007;15(4):986-93.

40. Nagahawatte NT, Goldenberg RL. Poverty, Maternal Health, and Adverse Pregnancy Outcomes. Annals of the New York Academy of Sciences. 2008;1136(1):80-5

41. Australian Institute of Health and Welfare. Australia's health 2014. Canberra: AlHW, 2014

\section{Submit your next manuscript to BioMed Central and take full advantage of:}

- Convenient online submission

- Thorough peer review

- No space constraints or color figure charges

- Immediate publication on acceptance

- Inclusion in PubMed, CAS, Scopus and Google Scholar

- Research which is freely available for redistribution 